\title{
Study of effect of sildenafil citrate in pregnant women with intrauterine growth restriction/oligohydramnios
}

\author{
Premalatha HL ${ }^{1}$, Raghupathi KMS ${ }^{1}$, Srinivas DNB ${ }^{2}$, Venkatesh ${ }^{3}$, Laxmi Kanth ${ }^{4}$
}

\author{
${ }^{1}$ Department of Obstetrics and Gynaecology, Hassan Institute of Medical Sciences, Hassan, Karnataka, India \\ ${ }^{2}$ Department of Pediatrics, Hassan Institute of Medical Sciences, Hassan, Karnataka, India \\ ${ }^{3}$ Radiologist and Sonologist, Hassan, Karnataka, India
}

Received: 14 July 2016

Accepted: 06 August 2016

\author{
*Correspondence: \\ Dr. Premalatha HL, \\ E-mail: premalatha.gowda@yahoo.in
}

Copyright: () the author(s), publisher and licensee Medip Academy. This is an open-access article distributed under the terms of the Creative Commons Attribution Non-Commercial License, which permits unrestricted non-commercial use, distribution, and reproduction in any medium, provided the original work is properly cited.

\begin{abstract}
Background: Fetal growth restriction affects up to $8 \%$ of all pregnancies with early onset and late onset fetal growth restriction with increased perinatal mortality. The objective of the study was to evaluate the effectiveness of Sildenafil citrate, the type 5 phosphodiesterase inhibitor which dilates myometrial arteries and improves uterine blood flow.

Methods: 100 pregnant women with severe early and late onset fetal growth restriction and oligohydramnios, from 2012 to 2015 at Hassan institute of medical sciences, Karnataka, India were selected for the study. Intervention included the administration of Sildenafil citrate $25 \mathrm{mg}$ three times daily until delivery and the major outcome variables were Doppler studies of Uterine artery, umbilical artery, MCA and ductus venosus, Amniotic fluid volume and gestational age. Pregnant women were in the age group of 18-36 years and between $22-34$ weeks of gestational age at the time of recruitment into the study. All the subjects were given intervention and monitored for primary outcome variables once in fifteen days with fetal Doppler and ultrasound techniques.

Results: Among the subjects students $2 \%$ resulted in stillbirths, $98 \%$ retained in the study up to delivery and $80 \%$ followed up to three years following delivery. Majority of the women (60\%) in the 30 weeks of gestational age and $10 \%$ among 22 weeks and 30\% between 32-36 weeks of gestation age showed USG abnormalities respectively. Among the USG abnormalities IUGR was found among $70 \%$ of women and $30 \%$ were found with oligohydramnios before intervention and became $0 \%$ and $10 \%$ after intervention respectively $(\mathrm{p}<0.005)$.

Conclusions: Study concludes that Sildenafil citrate would be useful to improve perinatal outcome in women with IUGR both early onset and late onset and Oligomnios.
\end{abstract}

Keywords: Intrauterine growth restriction/oligohydramnios, Sildenaphil citrate therapy, Perinatal outcome, Maternal outcome

\section{INTRODUCTION}

Currently there is no effective therapy for intrauterine growth restriction/placental insufficiency/ oligohydramnios. Doppler waveform analysis of pregnancies with fetal growth restriction suggests compromised uteroplacental circulation and hypo perfusion. Sildenafil citrate is type 5 phosphodiesterase inhibitor which dilates myometrial arteries and improves uterine blood flow. ${ }^{1}$ Sildenafil citrate enhances amino acid availability in the conceptus and fetal growth in an ovine model of intrauterine growth restriction. ${ }^{2}$ Women were offered Sildenafil citrate $(25 \mathrm{mg}$ three times daily until delivery), if their pregnancies were complicated by early onset IUGR (abdominal circumference $<5^{\text {th }}$ percentile), and oligohydramnios, between gestational age 22 weeks and 36 weeks. Sildenafil citrate treatment was associated with increased fetal AC growth, increase in liquor volume and alteration in Doppler changes with improved perinatal outcome and reduction in NICU (neonatal intensive care unit) admission. ${ }^{3}$ 


\section{METHODS}

In the district level medical institution like HIMS we have no specific treatment for patients facing dire prognosis with severe IUGR/Oligohydramnios. We conducted the study from 2012 to 2015 as innovative therapy to 100 women with severe early onset fetal growth restriction and oligohydramnios with Sildenafil citrate $25 \mathrm{mg}$ three times a day. This study was conducted after taking clearance from institutional ethical committee and written consent from the clients. Women were offered Sildenafil if their pregnancy was complicated by severe early onset IUGR (ultrasound estimation of fetal AC of $<5^{\text {th }}$ percentile) with an estimated probability of intact survival of less than $50 \%$, excluding known aneuploidy, anomaly, syndrome or congenital infection, or if there was plan to terminate the pregnancy. The clients with bad obstetric history with 22 weeks gestation, abnormal uterine artery Doppler, Oligomnios, clients with oligohydramnios and fetal growth restriction on routine anomalous scan, women with pregnancy induced hypertension were included in the study. Regular maternal assessment included measurement of BP. Proteinuria, complete blood count, weight gain, blood serum creatinine, uric acid aspartate transaminase, bilirubin, and albumin. Fetal assessment included fortnightly fetal Doppler studies, AFI, fetal biophysical profile twice a week and bi weekly NST. All patients were treated on outpatient basis till 36 weeks of gestation. Women were monitored for adverse side-effects such as headache, palpitation, flushing and visual disturbance. Decision for termination of pregnancy was made after standard clinical assessment. Betamethasone $12 \mathrm{mg}$ two doses at 24 hours apart were administered to all clients who have crossed 28 weeks of gestation to promote fetal lung maturity.

All clients underwent fetal Doppler and ultrasound once in 15 days after the Sildenafil administration. Uterine artery and umbilical artery, MCA and ductus venosus Doppler was done and any changes before and after administration of Sildenafil was noted down. Amniotic fluid volume, fetal AC was assessed once in 15 days for fetal growth velocity. Secondary outcomes for this study were gestational age at which the pregnancy terminated live births. Type of deliveries, neonatal survival to hospital discharge (without evidence of CNS injury, intra-ventricular haemorrhage, non CNS morbidity, retinopathy of prematurity, necrotizing enterocolitis). And babies were followed up for 3 years for development of milestones.

\section{RESULTS}

100 cases were studied from 22 weeks to 36 weeks. 10 cases were studied from 22 weeks, of which 8 cases continued their pregnancy for 8 weeks, and 2 stillbirths occurred. 60 cases were studied at 30 weeks, of which in 35 cases pregnancy continued for 6 weeks, in 10 cases pregnancy continued for 4 weeks and in 2 cases pregnancy continued for 2 weeks. 20 cases were studied from 32 weeks, of which in 10 cases pregnancy continued for 6 weeks, in 5 cases pregnancy continued for 4 weeks and in 5 cases pregnancy continued for 2 weeks. 10 cases were studied at 34 weeks, of which in 9 cases pregnancy continued for 2 weeks and in 1 case for 4 weeks with no fetal and maternal morbidity and mortality (Table 5).

Table 1: Base line characteristics of pregnancy outcome.

\begin{tabular}{|c|c|}
\hline $\begin{array}{l}\text { Maternal characteristics } \\
\text { maternal age nulliparous }\end{array}$ & $18-36$ years \\
\hline $\begin{array}{l}\text { Pregnancy characteristics } \\
\text { GA at eligibility } \\
\text { Uterine artery notching n\% } \\
\text { Umbilical artery Doppler - } \\
\text { EDF } \\
\text { Absent/reversed, n\% } \\
\text { AC }<3 \text { percentile at } \\
\text { eligibility } \\
\text { AFI }<50 \mathrm{~mm} \\
\text { No of PIH cases }\end{array}$ & $\begin{array}{l}22-34 \text { weeks } \\
30 \% \\
30 \%\end{array}$ \\
\hline $\begin{array}{l}\text { Maternal outcome - } \\
\text { Secondary development of } \\
\text { PIH } \\
\text { Maternal complications } \\
\text { headache, dizziness } \\
\text { palpitation }\end{array}$ & 40 cases \\
\hline $\begin{array}{l}\text { Fetal out come } \\
\text { Increased AC } \\
\text { Improved AFI } \\
\text { Doppler changes }\end{array}$ & $\begin{array}{l}70 \text { cases } \\
20 \text { cases } \\
30 \text { cases }\end{array}$ \\
\hline $\begin{array}{l}\text { Post eligibility/on sildenaphil } \\
\mathrm{n} \% \\
\text { Eligibility to delivery } \\
\text { interval (weeks) } \\
\text { GA at delivery weeks since } \\
\text { LMP }\end{array}$ & $<2$ weeks to 8 weeks \\
\hline $\begin{array}{l}\text { Perinatal outcome } \\
\text { Live births } \\
\text { Still births } \\
\text { Survival to hospital } \\
\text { discharge } \\
3 \text { years follow up }\end{array}$ & $\begin{array}{l}\text { No incidence of meconium } \\
98 \\
2 \\
98 \text { cases } \\
80 \text { cases }\end{array}$ \\
\hline
\end{tabular}

Table 2: Distribution of subjects according to USG abnormality at different gestational age.

\begin{tabular}{|ll|}
\hline Gestational age & USG abnormality n-100 \\
\hline 22 weeks & $10(10 \%)$ \\
\hline 30 weeks & $60(60 \%)^{*}$ \\
\hline 32 weeks & $20(20 \%)$ \\
\hline 34 weeks & $10(10 \%)$ \\
\hline $\begin{array}{l}\text { *Majority of USG abnormality was found at 30 weeks of } \\
\text { gestation (60\%) }\end{array}$
\end{tabular}

All clients underwent ultrasound scan, Table 2, Table 3, Table 4 shows percentage of USG abnormality at different gestational age, type of USG abnormalities, and doppler changes respectively. 
Table 3: Distribution of subjects according to type of USG abnormality.

\begin{tabular}{|ll|}
\hline Type of abnormality & Number $(\mathbf{n}-100)$ \\
\hline IUGR & $70(70 \%)$ \\
\hline Oligohydramnios & $30(30 \%)$ \\
\hline
\end{tabular}

After the Sildenafil therapy 70 cases showed improved AC values, AFI improved in 20 cases, remained same in 8 cases, decreased in 2 cases. In Doppler changes 20 cases showed reversal of uterine artery notching, 5 cases showed unilateral notching, 5 cases remained same with bilateral uterine artery notching. Umbilical artery Doppler 20 cases showed absent end diastolic flow before treatment but after therapy 10 cases showed improvement and 10 cases remained same. 10 cases which showed reversal of end diastolic flow before treatment, after treatment 8 showed improvement and 2 cases showed no improvement with the statistically significant from the baseline $(\mathrm{P}<0.05)$ (Table 5).

Table 4: Distribution of subjects according to type of Doppler changes during the study $(n=60)$.

\begin{tabular}{|ll|}
\hline Doppler changes & Number (n-60) \\
\hline Uterine artery notching & $30(50 \%)$ \\
\hline Umbilical artery absent flow & $20(30 \%)$ \\
\hline Umbilical artery reverse flow & $10(20 \%)$ \\
\hline
\end{tabular}

Effect of sildenafil citrate on IUGR, oligohydramnios and Doppler changes were statistically analysed using paired t-test. $\mathrm{P}$ value less than 0.05 was considered statistically significant.

Table 5: Continuation of pregnancy after intervention at different gestational age.

\begin{tabular}{|l|l|}
\hline Gestational age & Increased duration \\
\hline 22 weeks & $8 \pm 2$ weeks \\
\hline 30 weeks & $5 \pm 2$ weeks \\
\hline 32 weeks & $4 \pm 2$ weeks \\
\hline 34 weeks & $2 \pm 2$ weeks \\
\hline
\end{tabular}

Table 6: Effect of sildenafil citrate on IUGR, Oligomnios and Doppler changes.

\begin{tabular}{|lll|}
\hline Type of abnormality & Before & After \\
\hline IUGR & $70^{*}$ & 00 \\
\hline Oligohydramnios & $30^{*}$ & 10 \\
\hline Doppler changes & $60^{*}$ & 25 \\
\hline
\end{tabular}

*statistically significant from baseline $\mathrm{p}<0.05$

One IUD occurred due to abruption placenta at 37 wks. One neonatal death after 24 hours for milk aspiration. All other babies born between 28 to 37 weeks were followed up to 3 years with normal development.

\section{DISCUSSION}

To our knowledge this is one of the few studies to assess the potential benefit of Sildenafil to improve perinatal outcomes in pregnancies complicated with intrauterine growth restriction and Oligohydramnios. Sildenafil treatment improved perinatal outcome by improving fetal growth velocity as assessed by serial AC measurements by ultrasound. There was improvement in AFI and fetal Doppler parameters. ${ }^{4}$ Sildenafil therapy has improved the perinatal outcome, reduced NICU admissions and 3 years follow up shows no effect on the overall development of the babies. Maternal side effect is almost negligible. Those who complained of head ache and palpitation the dose of Sildenafil was reduced from three times a day to two times a day. Therefore Sildenafil represent a novel intervention for the pregnancies with IUGR. At present we don't have effective evidence based treatment for pregnancies with IUGR. Non-specific interventions include maternal lifestyle modifications, low dose aspirin, drugs which release nitric oxide, complete bed rest, hospital admission and surveillance or pregnancy termination $^{3}$. These widely practiced interventions are not based on evidence from randomized control trials. They are used in the belief that rest will improve uteroplacental circulation by stealing blood from gluteal and quadriceps. Preliminary evidence supports further investigations of calcium channel blockers, but not L-Arginine, to improve fetal growth. ${ }^{5}$

We chose fetal Doppler changes and AFI and AC growth percentiles to assess growth velocity. AC percentile was commonly $<5 \%$ for gestational age throughout the clinical course in our study population but there was an apparent relative improvement in fetal growth velocity with Sildenafil citrate. Our study shows improved AFI and disappearance of uterine artery notches, changes in the umbilical artery Doppler like disappearance of reduced end diastolic flow.

Our studies concur with the observed effect of Sildenafil on isolated resistance arteries from women with IUGR. This ex vivo effect was more marked for IUGR arteries than for those from women with preeclampsia and explains why there was greater benefit in women with IUGR than those with preeclampsia. ${ }^{6}$

\section{CONCLUSION}

In summary our study shows Sildenafil citrate may be useful to improve perinatal outcome in women with IUGR both early onset and late onset and oligomnios. Further our study showed no long term effect on mother and baby.

Funding: No funding sources

Conflict of interest: None declared

Ethical approval: The study was approved by the Institutional Ethics Committee 


\section{REFERENCES}

1. Panda S, Das A. Sildenafil Citrate in Fetal Growth Restriction. J Reprod Infertil. 2014;15(3):168-9.

2. Satterfield MC, Bazer FW, Spencer TE, Wu G. Sildenafil citrate treatment enhances amino acid availability in the conceptus and fetal growth in an ovine model of intrauterine growth restriction. J Nutr. 2010;140(2):251-8.

3. Von Dadelszen P, Dwinnell S, Magee LA. Sildenafil citrate therapy for severe early onset intrauterine growth restriction. BJOG. 2011;118:624-8.
4. Bilardo CM, Wolf H, Stigter RH. Relationship between monitoring parameters and perinatal outcome in severe, early intrauterine growth restriction. Ultrasound Obstet gynecol. 2004;23:11925.

5. Gulmerzoglu AM, Hofmeyr GJ. Calcium channel blockers for potential impaired fetal growth. Cochrane database syst Rev. 2000:2:CD000049.

6. Wareing M, Myers JE, O'Hara M, Baker PN. Sildenafil citrate enhances vasodilatation in fetal growth restriction. J Clin Endocrinol Metab. 2005;90(5):2550-5.

Cite this article as: Premalatha HL, Raghupathi KMS, Srinivas DNB, Venkatesh, Laxmi Kanth. Study of effect of sildenafil citrate in pregnant women with intrauterine growth restriction/ oligohydramnios. Int J Reprod Contracept Obstet Gynecol 2016;5:3094-7. 